International Journal of Agricultural Policy and Research Vol.10 (1), pp. 10-15, January 2022

Available online at https://www.journalissues.org/IJAPR/

https://doi.org/10.15739/IJAPR.22.002

Copyright (C) 2022 Author(s) retain the copyright of this article

ISSN 2350-1561

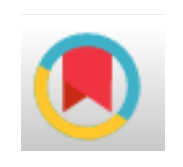

Original Research Article

\title{
Adoption level of integrated crop management practices among rice farmers: Does the adoption of production technology predict postharvest technology adoption
}

Ryan Mark A. Ambong

Occidental Mindoro State College, Philippines

Author's Email:

ryanmark.ambong2017@gmail.com

ORCID: https://orcid.org/00000001-5044-2913
SAMARICA is the second district of Occidental Mindoro province in the Philippines having a vast land area for rice production. It supports the rice milling sector of the province with promising facilities for postharvest of rice. This study investigates the rice farmers' adoption level of integrated crop management practices (ICMPs). The adoption ICMPs aims to promotes farm productivity and efficiency. A total of 404 rice farmers participated in this study selected through a multi-stage sampling technique. Quantitative data were generated from the survey questionnaire and were analyzed using Descriptive Statistics. Partial Least Square Structural Equation Modeling (PLS-SEM) was used to analyze the relationship between production and postharvest practices. The results revealed that rice farmers have "very high" adoption of rice production technologies except for water technologies and intermittent irrigation with "high" adoption level. In terms of postharvest, there is "very high" adoption of mechanized harvesting and recommended moisture content for rice but "moderate" adoption for rice parboiler, dying machines, and threshing of rice right after harvest. On the other hand, a statistically significant evidence was found for production technologies as predictor of postharvest technologies, specific for the care and management of rice $(\beta$ $=0.55 ; P<0.01$ ).

Keywords: Adoption, agricultural extension, integrated crop management, rice farming, technology

\section{INTRODUCTION}

Production and postharvest practices for rice include the use of modern rice varieties resistant to climate change and pest and diseases as well as mechanization of farm activities for productivity and efficiency. Javier (2017) mentioned that using modern varieties with proper irrigation will make irrigated lowland rice productive like the well-irrigated farms of Thailand, Vietnam, and Indonesia. On the other hand, Philippine rice is not competitive due to high labor costs, unlike Vietnam and Thailand. Unlike those countries, the Philippines use less tractors in land preparation, harvesting, and threshing. To attain competitiveness, the Philippines need to fully mechanize the rice production cycle starting from land preparation to transplanting, harvesting, threshing, and up to drying. In large areas of Thailand, Vietnam, and India, direct seeding technology is done instead of transplanting, which is more laborious. An agricultural policy that unifies different rice production technologies to attain higher productivity is called Integrated Crop Management (ICM). It is a holistic approach that includes both production and postharvest practices (Mariano et al., 2012).

Occidental Mindoro is the top rice-producing province in Mindoro, Marinduque, Romblon and Palawan (MIMAROPA) that produces more than 250,000 metric tons of paddy 
rice from about 60,000 hectares of land. Rice farming is the leading source of seasonal employment in the province by almost $80 \%$ of the total population including children (DAMIMAROPA, 2017).

Between the year 2000 and 2011, the Bureau of Agricultural Statistics (BAS) reported that Occidental Mindoro contributes about $27 \%$ of the total rice harvest in MIMAROPA. Within these years, Oriental Mindoro, Palawan, and Occidental Mindoro are the top three provinces in the region sharing the largest portion of the area harvested for rice. In terms of yield, Occidental Mindoro ranked as the highest yielding province. BAS (2012) reported that this high productivity was due to high adoption rate of certified inbred and hybrid seeds. In general adoption of hybrid seeds in MIMAROPA is minimal while adoption of certified seeds is moderate (BAS, 2012; Philippine Rice Research Institute, 2013). During the last quarter of 2018, the Philippine Statistics Authority (PSA, formerly known as BAS) reported that the country's rice production was 7.16 million metric tons. On the other hand, the MIMAROPA region contributed $17.18 \%$ of the country's total rice production while $28.56 \%$ of that came from Occidental Mindoro or about $4.89 \%$ of the country's total rice production (PSA 2018; Philippine Rice Research Institute, 2019).

For the last two decades, the rice farming activities in Occidental Mindoro have faced a significant challenge on the increasing production cost, mainly attributed to the rising price of farm inputs. There was also an uncertain claim that farm productivity declines due to the reduced application of essential agrochemicals (BAS, 2012). Farmers basically lessen the volume of farm inputs to keep up with the high financial requirements of the recommended rate of agrochemical applications for the cropping year. Moreover, irrigation system in some areas are no longer viable due to deforested watersheds and deficient river systems. Hence, irrigation is a serious operational problem for rice farmers and other crop producers.

Regarding postharvest, the Department of AgricultureMIMAROPA projects that rice milling facilities in the year 2019 would utilize 1,031,241 metric tons of rice using the growth rate of $1.63 \%$. At present, Occidental Mindoro rice milling facilities have a capacity of 329,090 metric tons of rice annually given $100 \%$ utilization. This is higher than the rice production capacity of the province of 319,143 metric tons of rice. Furthermore, the per capita consumption for rice in the MIMAROPA region is 108 kilograms per year and the total rural and urban population of the region is 2,963,360 (DA-MIMAROPA, 2017; Philippine Statistics Authority, 2017). Given these figures, the entire region is consuming about $320,042,880$ kilograms of rice in a year or approximately $320,042.88$ metric tons. Hence, there is a gap of 899.88 metric tons of rice given the production capacity of 319,143 metric tons.

SAMARICA is known for its vast land area for rice production that supports the rice milling sector of the province. Furthermore, it has a promising facility for the postharvest of rice. Based from the above ideas presented, this study aims to determine the level of adoption of the integrated crop management practices among rice farmers.

\section{Hypothesis}

$\mathrm{H}_{1}$ : The adoption of production technologies does not predict the adoption of postharvest technologies.

\section{MATERIALS AND METHODS}

\section{Respondents}

A survey was targeted at 400 rice farmers who were selected from the major rice producing barangays of SAMARICA, Occidental Mindoro using multi-stage sampling technique. According to the guidelines issued by the Centro Internacional de Mejoramiento de Maize y Trigo (CIMMYT), the suggested sample size for conducting formal surveys for agricultural technology adoption is between 60-120 respondents after 2-4 years of the release of a certain technology or initiation of extension program. Three stages of sampling were conducted which involved proportionate allocation, purposive selection and random selection. In the first stage, the proportionate allocation was utilized to allocate the four hundred questionnaires among the four municipalities of the SAMARICA area based on the total land area dedicated for rice farming in each municipality. The allocation scheme is anchored to the assumption that the number of farmers is positively related to the farm size (Asaduzzaman and Hossain, 2015). In the second stage, the farmer-respondents were selected based on the following criteria: the farmer must own the land, adopts monocropping, has experience in rice production for at least five years, has contact with extension agents, or attend training and seminars for not less than two years. In the third stage, the farmer-respondents were randomly selected from the chosen areas. Based on the original computation, the municipality of Rizal has a sample size of 56 farmer-respondents. However, the minimum sample size for adoption studies is suggested to be 60 (CIMMYT, 1993). Hence, from the initial sample size of 400 , a total of 404 respondents were targeted in this study to satisfy the minimum requirement. Table 1 summarizes the sampling scheme of the study.

\section{Data collection and analyses}

Integrated crop management practices for rice (also referred to as technologies or technological advancements) were solicited through literature review, expert advice, and validation. The available technologies for rice in the Philippine context were selected and sorted based on their applicability and diffusion in the study area. The selected rice technologies, which were further categorized as production and postharvest technology, served as the basis in the construction of the survey instrument. The finalized survey instrument underwent reliability testing using Cronbach's Alpha Coefficient (see Table 2)

Collected data were subjected to sorting and coding and were entered into Statistical Package for Social Sciences (SPSS) version 20. Data were analyzed using Descriptive Statistics such as Frequency and Measures of Central Tendency while Partial Least S quare Structural Equation 
Table 1. Sampling scheme of the study

\begin{tabular}{lccc}
\hline Municipality & $\begin{array}{c}\text { Estimated land area for rice } \\
\text { farming (ha) }\end{array}$ & $\begin{array}{c}\text { Estimated land area/Total land } \\
\text { area (\%) }\end{array}$ & Sample size \\
\hline San Jose & 19,428 & 51 & 204 \\
Magsaysay & 6,319 & 16 & 68 \\
Rizal & 5,279 & 14 & 60 \\
Calintaan & 7,220 & 19 & 76 \\
Total & $\mathbf{3 8 , 2 4 6}$ & $\mathbf{1 0 0}$ & $\mathbf{4 0 4}$ \\
\hline
\end{tabular}

Table 2. Reliability test result of the research instrument

\begin{tabular}{|c|c|c|c|c|c|}
\hline \multirow{2}{*}{ Items } & \multicolumn{2}{|c|}{ Item-construct loading } & \multirow{2}{*}{$\begin{array}{c}\text { Cronbach's } \\
\text { Alpha }\end{array}$} & \multirow{2}{*}{$\begin{array}{l}\text { Composite } \\
\text { reliability }\end{array}$} & \multirow{2}{*}{$\begin{array}{c}\text { Average } \\
\text { Variance } \\
\text { Extracted }\end{array}$} \\
\hline & Standardized & pvalue & & & \\
\hline $\begin{array}{l}\text { Production Technologies } \\
\text { Factor 1: Pre-planting }\end{array}$ & & & 0.850 & 0.887 & 0.529 \\
\hline Mechanized land preparation & 0.612 & $<0.001$ & & & \\
\hline Proper seedling establishment/seedbed preparation & 0.738 & $<0.001$ & & & \\
\hline Synchronous/timely transplanting & 0.768 & $<0.001$ & & & \\
\hline Use of certified inbred and/ or hybrid seeds & 0.712 & $<0.001$ & & & \\
\hline Use of modern rice varieties & 0.742 & $<0.001$ & & & \\
\hline Use of recommended seeding rates & 0.783 & $<0.001$ & & & \\
\hline Proper spacing of seedlings & 0.724 & $<0.001$ & & & \\
\hline Factor 2: Care and management & & & 0.791 & 0.882 & 0.719 \\
\hline Use of water technologies (supplemental irrigation) & 0.921 & $<0.001$ & & & \\
\hline Use of intermittent irrigation technique & 0.948 & $<0.001$ & & & \\
\hline Timely application of fertilizers and agrochemicals & 0.639 & $<0.001$ & & & \\
\hline Postharvest Technologies & & & 0.732 & 0.825 & 0.521 \\
\hline Mechanized harvesting & 0.313 & 0.004 & & & \\
\hline Use of modernized rice parboiler & 0.819 & $<0.001$ & & & \\
\hline Follow recommended moisture content & 0.397 & $<0.001$ & & & \\
\hline Threshing right after harvest & 0.898 & $<0.001$ & & & \\
\hline Use of drying machines (flatbed, mobile, flash) & 0.935 & $<0.001$ & & & \\
\hline
\end{tabular}

Table 3. ICMPs adopted by the rice farmers in terms of production activity

\begin{tabular}{|c|c|c|c|c|c|}
\hline Production Technology & $\mathrm{n}$ & Minimum & Maximum & Mean & SD \\
\hline Mechanized land preparation & 404 & 1 & 5 & 4.54 & .631 \\
\hline Proper seedling establishment/seedbed preparation & 404 & 2 & 5 & 4.39 & .626 \\
\hline Synchronous/timely transplanting & 404 & 2 & 5 & 4.42 & .615 \\
\hline Use of water technologies (supplemental irrigation) & 404 & 1 & 5 & 4.07 & 1.149 \\
\hline Use of intermittent irrigation technique & 404 & 1 & 5 & 4.08 & 1.166 \\
\hline Use of certified inbred and/ or hybrid & 404 & 1 & 5 & 4.57 & .612 \\
\hline Use of modern rice varieties & 404 & 2 & 5 & 4.56 & .601 \\
\hline Use of recommended seeding rates & 404 & 2 & 5 & 4.44 & .697 \\
\hline Proper spacing of seedlings & 404 & 1 & 5 & 4.52 & .681 \\
\hline Timely application of fertilizers and agrochemicals & 404 & 1 & 5 & 4.43 & .790 \\
\hline
\end{tabular}

Legend: $1.00-1.80=$ very low; $1.81-2.60=$ low; $2.61-3.40=$ moderate; $3.41=-4.20=$ high; $4.21-5.00=$ very high

Modeling (PLS-SEM) was used to analyze the relationship between production and postharvest practices.

\section{RESULTS AND DISCUSSION}

\section{Integrated crop management practices adopted by rice farmers}

The ICMPs, specifically the production and postharvest practices included in the survey instrument were identified through literature review and validation from the experts in rice production. From the pre-constructed instrument the set of production and postharvest practices was chosen by considering its diffusion and applicability in SAMARICA, Occidental Mindoro. There were pre-identified technologies but not yet disseminated and promoted to SAMARICA farmers and these were removed from the final survey instrument.

From Table 3, the survey reveals that rice farmers in SAMARICA, Occidental Mindoro have "very high" adoption of rice production technologies. Meanwhile, there is "high" 
Table 4. ICMPs adopted by the rice farmers in terms of postharvest activity

\begin{tabular}{|c|c|c|c|c|c|}
\hline Postharvest Technology & $\mathbf{N}$ & Minimum & Maximum & Mean & SD \\
\hline Mechanized harvesting & 404 & 1 & 5 & 4.75 & .597 \\
\hline Use of modernized rice parboiler & 404 & 1 & 5 & 2.92 & 1.699 \\
\hline Follow recommended moisture content & 404 & 1 & 5 & 4.26 & .957 \\
\hline Threshing right after harvest & 404 & 1 & 5 & 3.66 & 1.315 \\
\hline Use of drying machines (flatbed, mobile, flash) & 404 & 1 & 5 & 3.38 & 1.573 \\
\hline
\end{tabular}

Legend: $1.00-1.80=$ very low; $1.81-2.60=$ low; $2.61-3.40=$ moderate; $3.41=-4.20=$ high; $4.21-5.00=$ very high

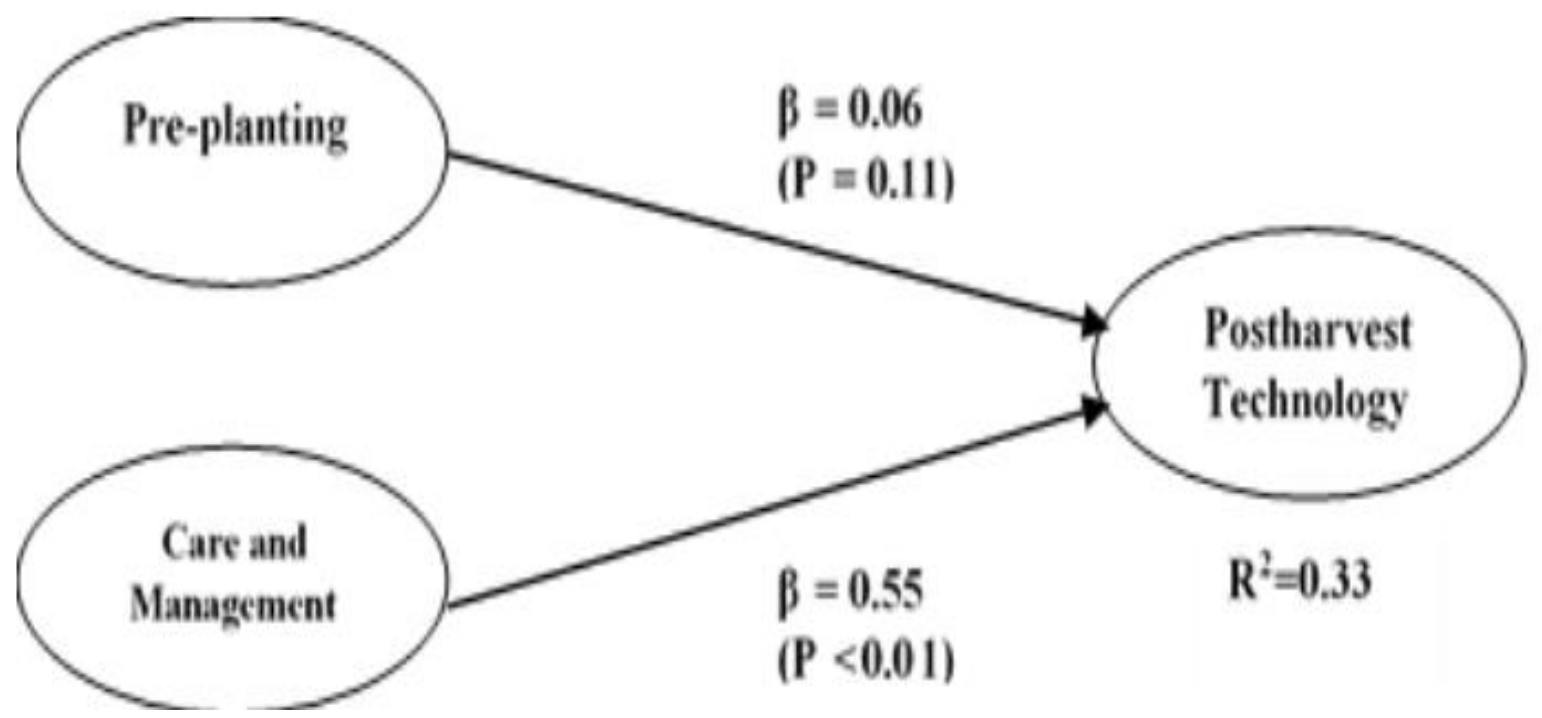

Figure 1: Outcome of hypothesized framework

adoption for the specific technologies such as water technologies and intermittent irrigation. In the study by Mariano, Villano, and Fleming (2012), about 49\% of the farmers surveyed adopt intermittent irrigation technique and the majority (90\%) adopt the use of modern rice varieties.

In the current study, it was found that rice farmers in SAMARICA highly adopt the use of certified inbred and/ or hybrid seeds with the highest mean of 4.57. This is supported by the report of Santiago et al. (2015) that majority of the rice farmers in Occidental Mindoro use Hybrid seeds specifically SL-8 $(57 \% ; n=100)$. The same finding is supported by this report that $80 \%$ of rice farmers in Occidental Mindoro adopt transplanting technique in crop establishment. According to IRRI (n.d), seeding rates are typically adequate between 40 to $100 \mathrm{~kg}$ per ha. In a recent report, Occidental Mindoro farmers adopt an average of $102 \mathrm{~kg}$ per ha of transplanted inbred rice and 24 $\mathrm{kg}$ for transplanted hybrid rice (Santiago et al., 2015) which are above and below the recommended rates. This corroborates with Mariano et al. (2012) who found a low adoption rate for the use of recommended seeding rates (24\%).

On the contrary, the current study found that SAMARICA farmers follow the recommended seeding rate with a mean of 4.44 interpreted as "very high". In terms of fertilizer and agrochemical application, Santiago et al. (2015) found that $94 \%$ of Occidental Mindoro farmers use insecticides and are also dependent on the use of Nitrogen (N) (171 kg/ha). Meanwhile, the current study supports the previous report that SAMARICA farmers have "very high" adoption of timely application of fertilizers and agrochemicals (mean $=4.43$ ).

The size of the farm area is positively related to the likelihood of adopting rice technologies (Akudugu et al., 2012; Mariano et al., 2012). Moreover, if a farmer owns farm assets such as land and machinery, they have the tendency of becoming a technology-adopter (Mariano et al. (2012). Additionally, Langyintuo and Mungoma (2008) argue that assets owned by farmers are a deciding factor in adopting technology. In terms of farm size, about $12 \%$ of the world's agricultural areas are classified as small farms ( $<2$ ha) which are family operated (Lowder et al., 2016). In the Philippines, rice production is highly dependent on manual labor and farm mechanization is low due to financial constraint of the majority of Filipino farmers (Suministrado, 2013; Bermudez et al., 2009; Mariano et al., 2009).

Occidental Mindoro has a basic farm characteristic of one rice-based farm parcel and the largest size is 1.55 ha. Majority of these farms are irrigated by the national irrigation system (Santiago et al., 2015). In terms of postharvest technology, the rice farmers in SAMARICA, Occidental Mindoro have "very high" adoption of mechanized harvesting and obey to the recommended moisture content for rice. However, they have "moderate" adoption of rice parboiler and dying machines (Table 4). 
Table 5. Empirical results for hypothesis

\begin{tabular}{|c|c|c|c|c|c|}
\hline Causal path & Hypothesis & $\begin{array}{l}\text { Expected } \\
\text { sign }\end{array}$ & $\begin{array}{c}\text { Path } \\
\text { coefficient }\end{array}$ & $\begin{array}{c}\text { p- } \\
\text { value }\end{array}$ & Interpretation \\
\hline Pre-planting technology $\rightarrow$ postharvest technology & $\mathrm{H}_{01} \mathrm{~A}$ & + & 0.064 & 0.112 & not significant \\
\hline Care and management $\rightarrow$ postharvest technology & $\mathrm{H}_{01} \mathrm{~B}$ & + & 0.546 & $<0.01$ & significant \\
\hline
\end{tabular}

They also moderately adopt the practice of threshing the rice right after harvest which is contrary to Mariano et al. (2009) who found 65\% adoption rate of this technology.

According to Santiago et al. (2015), Occidental Mindoro has an $88 \%$ adoption rate for combine harvester which was distributed by the Department of Agriculture (DA). The province has an average of 66.48 man-days/ha and the highest portion is devoted to crop establishment of 26.91 . Since there is high adoption rate for combine harvester, only 6.70 man-days/ha are dedicated for harvesting and threshing.

\section{Test of hypothesis}

In Figure 1, the indicators for production practices are further categorized to pre-planting and care and management practices.

Based on the result of PLS-SEM method, a statistically significant evidence was found for the $\mathrm{H}_{0} 1 \mathrm{~B}$ (Care and management $\rightarrow$ postharvest technology; $\beta=0.546, p<0.01$ ). The result suggests that the adoption of postharvest technology depends on the care and management practices of rice farmers (see Table 5).

\section{CONCLUSIONS}

Based from the findings, this research concludes that ICMPs have moderate to very high adoption level among rice farmers of SAMARICA, Occidental Mindoro. Furthermore, the care and management practices for rice determine the farmers' adoption of postharvest technologies. To improve the adoption rates of the extended technologies from moderate to high, the Local Government Unit (LGU), thru the Municipal Agriculture Office (MAO), should intensify the promotion of suitable, site-specific, and cost-efficient production and postharvest technologies to younger farmers who have lesser experience compared to old farmers. Likewise, adoption can be costly to most farmers that is why financial assistance from the LGU must be provided to farmers who cannot afford shifting from traditional to modern farming practices. Extension providers should build and promote positive attitude of farmers towards ICMPs by providing compensation packages that will ensure better rice yield. Relevant extension programs are also necessary to capacitate farmers in managing technologies. Demonstration farms should also be established since farmers are ageing and mostly rely on their own experience. They would not believe in adopting the ICMPs unless it is explained and demonstrated to them.

\section{Conflict of interests}

The authors declare that they have no conflicting interests.

\section{REFERENCES}

Akudugu MA, Guo E,Dadzie SK (2012). Adoption of Modern Agricultural Production Technologies by Farm Households in Ghana: What Factors Influence their Decisions? J. Biol. Agric. Healthcare, 2(3):1-13.

Asaduzzaman M, Hossain T (2015). Adoption of Selected Homestead Agricultural Technologies by the Rural Women in Madhupur Upazila under Tangail District. Japanese Institutional Repositories Online.

BAS. 2012. CountrySTAT. http://countrystat.bas.gov.ph/.

Bermudez RV, Francisco SR, Mataia AB, Malasa RB (2009). Mechanization in the Philippine Rice Production: Philippine Rice Research Institute.

CIMMYT Economics Program. (1993). The Adoption of Agricultural Technology: A Guide for Survey Design. Mexico, D.F.: CIMMYT.

DA-MIMAROPA. (2017). About Us: Department of Agriculture. Retrieved April 25, 2018, from Department of Agriculture Regional Field Office IV-MIMAROPA: darfu4b.da.gov.ph

Department of Agriculture-Philippines. (2013). DA allots P500M to promote hybrid rice. Manila: Official GazetteOffice of the President.

IRRI. (n.d.). Rice Knowledge Bank. Retrieved from Knowledgebank.irri:

http://www.knowledgebank.irri.org/decision-tools/ricedoctor/rice-doctor-fact-sheets/item/seed-high-rate

Javier EQ (2017, May 7). What to do about rice. The Manila Bulletin. Retrieved October 1, 2018, from $<$ https://www.pressreader.com/philippines/manila bulletin/20170507/282029032138695>

Langyintuo S, Mungoma C (2008). "The effect of household wealth on the adoption of improved maize varieties in Zambia," Food Policy, Elsevier, vol. 33(6):550-559,

Lowder SK, Skoet J, Raney T (2016). The Number, Size, and Distribution of Farms, Smallholder Farms, and Family Farms Worldwide. World Development, 16-29.

Mariano MJ, Villano R, Fleming E (2012, January). Factors influencing farmers' adoption of modern rice technologies and good management practices in the Philippines. Agricultural Systems, 105(1): 41-53.

Philippine Rice Research Institute. (2013). Region IVB Rice Industry Primer Series. Science City of Munoz, Nueva Ecija: Philippine Rice Research Institute.

Santiago J, Yusongco C, Beltran J, Relado R (2015). Socio- 
economic profile of Mindoro farmers: Baseline Characterization of PhilRice-Mindoro Satellite Station. Los Banos, Laguna: Philippine Rice Reserach Institute.

Suministrado DC (2013). Status of Agricultural Mechanization in the Philippines. Regional Forum on Sustainable Agricultural Mechanization in teh Asia and the Pacific. Quingdao, China. 